\title{
The comeback of vaginal surgery during and after the COVID-19 pandemic: a new paradigm
}

\author{
Gautier Chene $^{1,2}$ (D) Emanuele Cerruto ${ }^{1} \cdot$ Erdogan Nohuz $^{1}$ \\ Received: 16 June 2020 / Accepted: 23 July 2020 / Published online: 29 July 2020 \\ (C) The International Urogynecological Association 2020
}

Minimally invasive procedures including vaginal and laparoscopic hysterectomy should be performed in preference to abdominal hysterectomy (fewer adverse events, shorter hospital stay). Moreover, when comparing the vaginal route to the laparoscopic approach, vaginal hysterectomy should be the gold standard (shorter operating time, fewer urinary tract injuries, cost-effective advantages). However, the prevalence of vaginal hysterectomies has dropped worldwide for the past several years because of difficulties in training and teaching the vaginal procedures and exciting new laparoscopic equipment (3D laparoscopy, relevant energy-driven devices, development of robotic-assisted surgery) [1].

With the COVID-19 crisis, laparoscopic surgery is not without risk:

(1) Many concerns have been raised about the risk of SARS$\mathrm{CoV}-2$ transmission by symptomatic and asymptomatic carriers to healthcare workers during tracheal intubation (due to higher viral loads in the respiratory tract). SARSCov- 2 (size between 0.06 to $0.14 \mu \mathrm{m}$ ) may be present in droplets and aerosols during airway manipulation as well as in conjunctival secretions. Closer contact with patients therefore carries higher risk of contamination for anesthesia staff [2].

A specific strategy has been proposed with personal protective equipment (PPE) (N95 masks, eye protection with goggles or face shield, fluid-resistant gown, gloves) and guidelines for anesthesia procedures

Gautier Chene

chenegautier@yahoo.fr

1 Department of Gynecology and Obstetrics, Hôpital Femme Mère Enfant, HFME, 59 boulevard Pinel, Hospices civils de Lyon, 69000 Lyon, France

2 Université Claude Bernard Lyon 1, EMR 3738, 69000 Lyon, France (relevant institutional algorithm to design airway manipulation sequences such as rapid sequence induction). The American Society of Anesthesiologists also reported reducing the number of surgical procedures because of the shortage of PPE and the lack of induction and paralysis treatment [3]. But until when?

(2) Another potential risk of viral transmission may be related to the surgical smoke during laparoscopic procedures. By analogy, HBV and HPV have been found in these aerosols. Since the size of HBV and HPV (respectively, $0.04 \mu \mathrm{m}$ and $0.05 \mu \mathrm{m}$ ) is smaller than that of SARSCov-2, the latter may be present in these surgical aerosols. Guidelines have been published about smoke and gas evacuation during laparoscopy (appropriate PPE and smoke evacuation devices with specific filtration systems) [4].

Vaginal surgery appears to be much less risky: SARS$\mathrm{CoV}-2$ is not detectable in the vaginal fluid of infected patients [5]. There is no need for general anesthesia (aerozilation risk, shortage of anesthesia drugs); regional and spinal anesthesia is sufficient. There is also no need to use bipolar vessel sealing devices, which may generate aerosols with hypothetical risk of viral transmission. We should therefore use traditional technical suturing.

After reading all these arguments, it is really time to relearn and perform the basic and effective techniques of vaginal surgery. 
Author contributions G Chene: Project development and manuscript writing.

E. Cerruto: Project development and manuscript writing.

E. Nohuz: Project development and manuscript writing.

\section{Compliance with ethical standards}

\section{Conflict of interest None.}

\section{References}

1. Chrysostomou A, Djokovic D, Edridge W, van Herendael BJ. Evidence-based guidelines for vaginal hysterectomy of the International Society for Gynecologic Endoscopy (ISGE). Eur J Obstet Gynecol Reprod Biol. 2018;231:262-7.
2. Tang LY, Wang J. Anesthesia and COVID-19: what we should know and what we should do. Semin Cardiothorac Vasc Anesth. 2020;24(2):127-37.

3. COVID-19: American Society of Anesthesiologists. Recommendations for anesthesia management. https://www. ascassociation.org/asca/resourcecenter/latestnewsresourcecenter/ covid-19/covid-19-anesthesia-recommendations

4. Resources for smoke \& gas evacuation during open, laparoscopic and endoscopic procedures. https://www.sages.org/resourcessmoke-gas-evacuation-during-open-laparoscopic-endoscopicprocedures/

5. Qiu L, Liu X, Xiao M, et al. SARS-CoV-2 is not detectable in the vaginal fluid of women with severe COVID-19 infection. Clin Infect Dis 2020; ciaa375.

Publisher's note Springer Nature remains neutral with regard to jurisdictional claims in published maps and institutional affiliations. 